\title{
Ethnic differences in the +405 and -460 vascular endothelial growth factor polymorphisms and peripheral neuropathy in patients with diabetes residing in a North London, community in the United Kingdom
}

\author{
Karima Zitouni ${ }^{1 *}$ (D) Lorna Tinworth ${ }^{2}$ and Kenneth Anthony Earle ${ }^{1,3}$
}

\begin{abstract}
Background: There are marked ethnic differences in the susceptibility to the long-term diabetic vascular complications including sensory neuropathy. The vascular endothelial growth factor (VEGF) +405 (C/G) and -460 (T/C) polymorphisms are associated with retinopathy and possibly with nephropathy, however no information is available on their relationship with peripheral neuropathy. Therefore, we examined the prevalence of these VEGF genotypes in a multi-ethnic cohort of patients with diabetes and their relationship with evident peripheral diabetic neuropathy.

Methods: In the current investigation, we studied 313 patients with diabetes mellitus of African-Caribbean, Indo-Asian and Caucasian ethnic origin residing in an inner-city community in London, United Kingdom attending a single secondary care centre. Genotyping was performed for the VEGF +405 and VEGF -460 polymorphisms using a pyrosequencing technique.

Results: Forty-nine patients (15.6\%) had clinical evidence of peripheral neuropathy. Compared to Caucasian patients, African-Caribbean and Indo-Asian patients had lower incidence of neuropathy $(24.6 \%, 14.28 \%, 6.7 \%$, respectively; $P=0.04)$. The frequency of the VEGF +405 GG genotype was more common in Indo-Asian patients compared to African-Caribbean and Caucasian patients $(67.5 \%, 45.3 \%, 38.4 \%$, respectively; $p \leq 0.02)$. The $\mathrm{G}$ allele was more common in patients with type 2 diabetes of Indo-Asian origin compared to African-Caribbean and Caucasian origin $(p \leq 0.02)$. There was no difference between the ethnic groups in VEGF -460 genotypes. The distributions of the VEGF +405 and VEGF -460 genotypes were similar between the diabetic patients with and without neuropathy.

Conclusions: In this cohort of patients, VEGF +405 and VEGF -460 polymorphisms were not associated with evident diabetic peripheral neuropathy, however an association was found between VEGF +405 genotypes and Indo-Asian which might have relevance to their lower rates of ulceration and amputation. This finding highlights the need for further investigation of any possible relationship between VEGF genotype, circulating VEGF concentrations and differential vulnerability to peripheral neuropathy amongst diabetic patients of different ethnic backgrounds.
\end{abstract}

Keywords: Diabetes, Peripheral neuropathy, Ethnicity, VEGF, Gene polymorphism, Pyrosequencing, Microvascularization

\footnotetext{
*Correspondence: kzitouni@sgul.ac.uk

'Department of Cellular and Molecular Medicine, St. Georges University of

London, London, UK

Full list of author information is available at the end of the article
} 


\section{Background}

Peripheral neuropathy affects up to $50 \%$ of patients with diabetes [1]. It is a major risk factor that makes diabetes responsible for $50-75 \%$ of non-traumatic amputations in the world $[2,3]$. The pathogenesis of diabetic neuropathy is poorly understood, but is likely to be multifactorial, a result of genetic susceptibility, environmental and lifestyle factors $[4,5]$.

There is increasing evidence that the prevalence of peripheral neuropathy as a complication of diabetes varies according to race/ethnicity. The North American and European studies of multi-ethnic groups have found a greater prevalence of neuropathy occurring in Caucasian patients compared to other ethnic groups [6]. Population based studies in the United Kingdom (UK) have reported lower rates of peripheral neuropathy in patients with type 2 diabetes of Indo-Asian and African-Caribbean origin compared with those of Caucasian origin [7-9]. Studies showing evidence of increased skin microvascularization in Indo-Asian subjects has been considered a cause for the lower rates of neuropathy compared with Caucasian subjects [10]. These findings were independent of glycaemic control and traditional risk factors for vascular disease, suggesting that genetic, or some other, as yet unidentified protective factor(s) may be relevant to these observations.

Strict metabolic control of hyperglycaemia is essential in preventing the onset and progression of diabetic neuropathy [2, 3]. Hyperglycaemia disrupts sensory nerve function through several mechanisms including, local hypoxia, activation of protein kinase $\mathrm{C}$, formation of advanced glycation end products, oxidative stress and pro-inflammatory changes $[4,5]$. A counter-response to these metabolic perturbations is the stimulation of gene expression of the angiogenic cytokine, Vascular Endothelial Growth Factor (VEGF) which attempts to alleviate hypoxia and improve nutrient supply.

A positive correlation has been reported between stimulated peripheral blood mononuclear cell VEGF protein production and the +405 GC VEGF gene polymorphism [11]. The highest VEGF protein production was noted in individuals who were +405 GG homozygous, while the lowest production was seen in subjects who were +405 CC. In patients with diabetes, several authors have shown associations between the VEGF +405 and VEGF -460 genotypes with microvascular and macrovascular complications [12-16]. However, no study has yet investigated the relationship of these polymorphisms and the vulnerability to diabetic neuropathy.

Therefore, the aim of this study is to determine the distribution of VEGF +405 and VEGF -460 gene (Genebank numbers rs2010963 and rs833061) polymorphisms in Indo-Asian, African-Caribbean, and Caucasian patients with diabetes and examine the relationship with clinical evidence of diabetic peripheral neuropathy.

\section{Methods}

\section{Patients}

The study was conducted at a secondary care centre in North London, UK, serving an inner-city community of 154,000 adults. Consecutive adult, attendees to the diabetes unit of Caucasian, Indo-Asian or African-Caribbean ethnicity were invited to take part in the study. Patients were considered to be of African-Caribbean or Indo-Asian ethnicity if both parents were native to either African or Caribbean countries or India, Pakistan, Bangladesh or Sri Lanka respectively. The parents of white, Caucasian patients were native of Western European or Mediterranean countries. A diagnosis of type 2 diabetes was based on an absence of ketosis or need of insulin within 1 year of diagnosis. Type 1 diabetes was confirmed in each subject on the basis of the diagnosis being made at less than 35 years of age with a history of ketosis at presentation and continuous use of subcutaneous insulin within 1 year from diagnosis. Patients with history of malignancy were excluded.

Patients were diagnosed as having peripheral sensory neuropathy if they had diminished sensation to light touch with the $10 \mathrm{~g}$ monofilament or to pinprick. Body mass index (BMI) was calculated from weight in kilograms divided by height in meters squared. Sitting blood pressure was measured after 10 min rest using a validated automated machine (OMRON 705HEM CP; OMRON Healthcare, West Sussex, U.K.) using an appropriate cuff size.

Fasting venous blood was taken from an antecubital vein. Glycosylated Haemoglobin A1c (HbA1c) was measured by a high-performance liquid chromatography system (Menarini 8140; Menarini Diagnostics, Wokingham, U.K.). Total cholesterol, HDL cholesterol and total triglycerides were estimated using enzymatic methods (Boehringer-Mannheim, Mannheim, Germany). The samples were coded in order to blind the laboratory staff to the patients' sex, age, racial origin, diabetes, and comorbidity status.

The study was approved by the ethics committee of the Whittington Hospital National Health Service Trust. Written, informed consent was provided by all patients entering the study.

\section{DNA extraction}

A modification of the method described by Miller et al. [17] was used. Briefly, $1 \mathrm{~mL}$ of the blood collected in sodium citrate and stored at $-80{ }^{\circ} \mathrm{C}$ was re-suspended in $2 \mathrm{~mL}$ of erythrocyte lysis solution $(1.44 \mathrm{mM}$ ammonium chloride, $1 \mathrm{mM}$ sodium bicarbonate) and the suspension centrifuged at $15,000 \times g$ for $2 \mathrm{~min}$. The supernatant was discarded, and the pellet was re-suspended in $0.64 \mathrm{~mL}$ nuclear lysis buffer [(10 mM Tris- $\mathrm{HCl}(\mathrm{pH}=8.2), 0.4 \mathrm{M}$ sodium chloride, $2 \mathrm{mM}$ di-sodium EDTA $(\mathrm{pH}=8.0)$ ], $0.18 \mathrm{~mL}$ sodium chloride, and chloroform. The samples 
were shaken vigorously and centrifuged at $10,000 \times \mathrm{g}$ for $3 \mathrm{~min}$. The supernatant containing the DNA was transferred into new eppendorf tubes and $1 \mathrm{~mL}$ of $100 \%$ ethanol was added and the tubes were inverted repeatedly. The samples were centrifuged for $2 \mathrm{~min}$ at $10,000 \times \mathrm{g}$. The supernatant was discarded and the pellet, containing DNA was dissolved in \%70 ethanol and the samples were centrifuged at $10,000 \times \mathrm{g}$ for $2 \mathrm{~min}$. The upper layer was then removed and polymerase chain reaction (PCR) grade water was added. The concentration and purity of DNA was measured using a NanoDrop spectrophotometer (NanoDrop Technologies, Wilmington, DE).

\section{Polymerase chain reaction}

Polymerase chain reaction procedure was performed in a total volume of $25 \mu \mathrm{L}$ reaction mixture that contained "Red Hot" Taq DNA polymerase enzyme (0.5 U), genomic DNA (250 ng), 20 pmol of each primer set (sequences shown in Table 1) and $\mathrm{Mg} 2+(1.5 \mathrm{mM})$.

All PCR mixes were amplified with the same touch down program: Denature at $95{ }^{\circ} \mathrm{C}$ for 5 min followed by 35 cycles of [denaturation $\left(95{ }^{\circ} \mathrm{C}\right.$ for $\left.1 \mathrm{~min}\right)$, annealing $\left(55^{\circ} \mathrm{C}\right.$ for $\left.1 \mathrm{~min}\right)$ and extension $\left(72{ }^{\circ} \mathrm{C}\right.$ for $\left.1 \mathrm{~min}\right)$ ] and a final step of extension at $72{ }^{\circ} \mathrm{C}$ for $10 \mathrm{~min}$.

\section{Pyrosequencing}

PCR product $(10 \mu \mathrm{L})$ was immobilised onto sepharose streptavidin-coated beads (Amersham Bioscience, Amersham, UK) suspended in binding buffer $(10 \mathrm{mM}$ Tris- $\mathrm{HCl}$, $2 \mathrm{M} \mathrm{NaCl}, 1 \mathrm{mM}$ EDTA, 0.1\% Tween 20, $\mathrm{pH}$ 7.6) and water to a total volume of $70 \mu \mathrm{L}$, at room temperature $\left(21^{\circ} \mathrm{C}\right.$ ) for $5 \mathrm{~min}$. Single-stranded (ss) DNA was obtained by washing the immobilised PCR product for $5 \mathrm{~s}$ successively in $70 \%$ ethanol, $0.2 \mathrm{M} \mathrm{NaOH}$ and washing buffer (10 mM Tris-acetate) followed by $12 \mu \mathrm{L}$ annealing buffer (20 mM Tris-Acetate, $5 \mathrm{mM}$ magnesium acetate, $\mathrm{pH}$ 7.6) containing 3.0 $\mu \mathrm{M}$ sequencing primer (Table 1 ) in a 96well PSQ HS plate. The primer was annealed to the ssDNA template by heating the plate at $80{ }^{\circ} \mathrm{C}$ for $2 \mathrm{~min}$, then allowing it to cool at room temperature $\left(21^{\circ} \mathrm{C}\right)$. Pyrosequencing analysis was carried out using the PSQ96 HS 96A instrument and the SNP Reagent kit containing dNTPs, enzyme and substrate mixtures according to manufacturer's protocols (Pyrosequencing AB, Uppsala, Sweden).

\section{Statistics}

Data were analysed using SPSS 19 (SPSS, Chicago, IL, USA). Biochemical and clinical data are expressed as mean \pm standard deviation. Continuous data were analysed with parametric or non-parametric tests according to the distribution. The chi-square test was used to compare the categorical data, genotyping and allelic distributions between patients with neuropathy and without, genotyping and allelic distributions between the ethnic groups. Logistic regression analysis was performed with neuropathy as the dependent variable to analyse the effect of ethnic group, VEGF genotype and glycated haemoglobin. A value of $p \leq 0.05$ was accepted as significant.

\section{Results}

Three hundred and thirteen diabetic patients were included in this study, of which forty nine $(15.6 \%)$ patients had peripheral neuropathy (Table 2). The prevalence of peripheral neuropathy was highest in the Caucasian group (24.6\%) compared to the African-Caribbean (14.28\%) and the Indo-Asian ethnic groups (6.7\%) $(P=0.04)$ (Fig. 1). Patients from the Caucasian origin had more type 1 diabetes per comparison to African-Caribbean and Indo-Asian patients, while the latter had less proportion of smokers per comparison to the other ethnic groups (Table 3).

The patients with peripheral neuropathy had significantly longer duration of diabetes, were older, taller and were more likely to be men. There were no significant differences in HbA1c as a measure of glycemic control, total cholesterol, HDL-cholesterol, and triglyceride levels between the two groups of patients. The groups had similar BMI, levels of systolic and diastolic blood pressure, treatment for hypertension and smoking history (Table 2).

\section{VEGF +405 and $-\mathbf{4 6 0}$ polymorphisms and ethnic group}

There was a marked disparity in the distribution of the VEGF +405 genotypes between the Indo-Asian, AfricanCaribbean, and Caucasian patients (Table 4). The VEGF +405 GG was more common in Indo-Asians (67.5\%) compared to African-Caribbean (45.3\%) and Caucasian patients (38.4\%) ( $p \leq 0.05$ and $p \leq 0.005$, respectively). The $\mathrm{G}$ allele was more common while the $\mathrm{C}$ allele was less common in the Indo-Asian group per comparison to the African-Caribbean and Caucasian ethnic groups ( $p \leq 0.02$ and $p \leq 0.005$, respectively). There were no

Table 1 Primer sequences

\begin{tabular}{lll}
\hline & VEGF +405 & VEGF-460 \\
\hline Forward primers sequence $\left(5^{\prime}-3^{\prime}\right)$ & GAGAAGTCGAGGAAGAGAGAGACG & AATGGAGCGAGCAGCGTCTT \\
Reverse primer sequence $\left(5^{\prime}-3^{\prime}\right)$ & CCCCAAAAGCAGGTCAC & CGTTCCCTCTTGCTAGGAATAT \\
Sequencing primers(5'-3') & GTGCGAGCAGCGAAA & TGCGTGTGGGGTTGA \\
\hline
\end{tabular}


Table 2 Demographic and clinical characteristics of diabetic patients with and without peripheral neuropathy

\begin{tabular}{lll}
\hline $\begin{array}{l}\text { DEMOGRAPHIC/CLINICAL } \\
\text { parameters }\end{array}$ & $\begin{array}{l}\text { With Neuropathy } \\
(n=49)\end{array}$ & $\begin{array}{l}\text { Without neuropathy } \\
(n=264)\end{array}$ \\
\hline Age (years) & $67.48 \pm 8.18^{* *}$ & $60.60 \pm 11.29$ \\
Diabetes(Type1/Type2)\% & $8.6 / 91.4$ & $12.9 / 87.1$ \\
Duration of diabetes (years) & $22.16 \pm 9.45^{* *}$ & $15.73 \pm 8.01$ \\
Gender (male/female)\% & $65.6 / 34.4^{*}$ & $46.6 / 52.9$ \\
Smoking history (yes/No) \% & $78.1 / 21.9$ & $73.8 / 26.2$ \\
Caucasian/African-Caribbean/ & $77.55 / 18.36 / 4.08^{*}$ & $58.50 / 27.35 / 14.15$ \\
Indo-Asian (\%) & & \\
Systolic blood pressure (mmHg) & $143.04 \pm 20.77$ & $144.16 \pm 21.68$ \\
Diastolic blood pressure (mmHg) & $77.36 \pm 10.14$ & $81.14 \pm 11.24$ \\
Hypertensive (\%) & 65.3 & 65.1 \\
Total Cholesterol (mmol/L) & $4.5 \pm 1.4$ & $4.67 \pm 1.19$ \\
HDL-Cholesterol (mmol/L) & $1.19 \pm 0.29$ & $1.43 \pm 0.41$ \\
Triglycerides(mmol/L) & $2.33 \pm 1.99$ & $1.99 \pm 1.4$ \\
BMI (Kg/m2) & $31.98 \pm 4.86$ & $31.03 \pm 6.57$ \\
HbA1c \% (mmol/mol) & $8.07 \pm 1.52$ & $8.00 \pm 1.59$ \\
& $(65 \pm 5.0)$ & $(64 \pm 11.0)$ \\
\hline
\end{tabular}

Data expressed as mean \pm SD

${ }^{*} p \leq 0.05$

${ }^{* *} p \leq 0.001$

interethnic differences in VEGF -460 genotypes (data not shown).

\section{VEGF +405 and VEGF $-\mathbf{4 6 0}$ gene polymorphisms and peripheral neuropathy}

Genotype frequencies for the +405 CG at the exon 1 of VEGF gene between patients with peripheral neuropathy and without peripheral neuropathy are shown in Table 5.

In the analysis of patients with type 2 diabetes only cohort $(n=253)$, there was no statistically significant difference in the VEGF +405 genotype distribution nor the $\mathrm{C}$ and $\mathrm{G}$ Allele frequencies $(p=0.76)$ between the patients with and without peripheral neuropathy (Table 5).

There was no statistically significant difference between $\mathrm{C}$ and $\mathrm{T}$ alleles $(p=0.73)$ and genotype frequency of the $-460 \mathrm{C} / \mathrm{T}$. The analyses also failed to find an association between $\mathrm{G}, \mathrm{C}$ alleles $(p=0.99)$ or $+405 \mathrm{C} / \mathrm{G}$ VEGF polymorphism between patients with and without peripheral neuropathy (Table 5). In the logistic regression analysis model with peripheral neuropathy as the dependent variable we tested the association between the VEGF +405 polymorphism and the quality of diabetes control HbA1c. The odds ratio (95\% confidence interval) was 0.67 (0.47-0.97) for patients of non-Caucasian origin $(p=0.035)$ and $1.25(1.04-1.50)$ for $\mathrm{HbA} 1 \mathrm{c}(p=0.015)$.

\section{Discussion}

We found that the distribution of the genetic polymorphisms of VEGF +405 and VEGF-460 varied with ethnic origin, but differences were not found to be associated with the presence of peripheral neuropathy in this cohort of patients with diabetes. Patients of non-Caucasian origin were $33 \%$ less likely to have peripheral neuropathy compared to Caucasian patients after correcting for HbA1c.

In recent years, the association of VEGF and diabetic neuropathy has attracted much attention. Vascular endothelial growth factor is an angiogenic cytokine that can be induced by hypoxia and increases capillary permeability, promote the synthesis of extracellular matrix and promote the proliferation and hypertrophy of endothelial cells [18]. However, VEGF can have deleterious effects on the basement membrane of vessels, increasing endoneurial vascular permeability, leading to nerve fibre ischemia and hypoxia, and thus contributing to the occurrence of neuropathy $[19,20]$.

In animal models of diabetes and neuropathy, increased VEGF staining has been reported in neuronal cell bodies

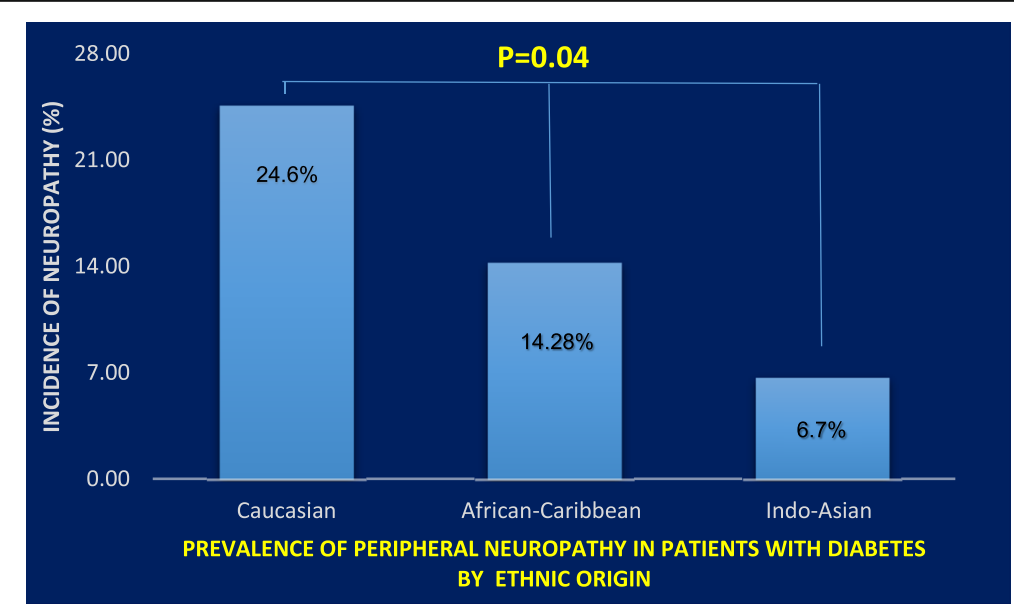

Fig. 1 Prevalence of peripheral neuropathy in patients with diabetes from Caucasian, African Caribbean and Indo-Asian origin) 
Table 3 Demographic and clinical characteristics of Indo-Asian, African-Caribbean and Caucasian patients

\begin{tabular}{llll}
\hline DEMOGRAPHIC/CLINICAL parameters & Indo-Asian & African-Caribbean & Caucasian \\
\hline Age (years) & $59.47 \pm 10.62$ & $56.49 \pm 12.06$ & $56.90 \pm 15.78$ \\
Diabetes(Type1/Type2)\% & $6.06 / 93.94$ & $3.08 / 96.92$ & $21.47 / 78.53^{*}$ \\
Duration of diabetes (years) & $17.34 \pm 7.26$ & $15.42 \pm 8.65$ & $16.66 \pm 10.27$ \\
Gender (male/female)\% & $61.8 / 38.2$ & $43.8 / 56.2$ & $57.5 / 42.5$ \\
Smoking history (yes/No) \% & $51.9 / 48.1$ & $73.7 / 26.7$ & $76.1 / 23.9^{*}$ \\
Systolic blood pressure (mmHg) & $147.82 \pm 24.42$ & $145.62 \pm 21.33$ & $140.33 \pm 23.02$ \\
Diastolic blood pressure(mmHg) & $82.33 \pm 10.70$ & $83.35 \pm 12.62$ & $79.11 \pm 11.09$ \\
Total Cholesterol (mmol/L) & $4.73 \pm 0.91$ & $4.59 \pm 1.18$ & $4.98 \pm 0.92$ \\
HDL-Cholesterol (mmol/L) & $1.3 \pm 0.64$ & $1.42 \pm 0.36$ & $1.35 \pm 0.36$ \\
Triglycerides (mmol/L) & $2.22 \pm 1.12$ & $1.67 \pm 0.94$ & $2.140 \pm 1.13$ \\
Height (m) & $1.62 \pm 0.10$ & $1.65 \pm 0.09$ & $1.66 \pm 0.11$ \\
BMI (Kg/m2) & $27.37 \pm 4.57$ & $30.73 \pm 6.43$ & $31.66 \pm 7.37$ \\
HbA1c \% & $7.5 \pm 1.24$ & $8.33 \pm 1.78$ & $7.9 \pm 1.62$ \\
\hline Da exprese & &
\end{tabular}

Data expressed as mean \pm SD

${ }^{*} p \leq 0.005$

in dorsal root ganglia, axons and in Schwann cells of peripheral nerves, also, higher circulating levels of the cytokine have been reported in comparison to healthy animals [21, 22]. Treatment with plasmid DNA encoding for VEGF was shown to improve sensory behavioural features and sciatic nerve blood flow [20]. Clinical studies using the intramuscular plasmid VEGF gene transfer have been shown to improve neuropathic symptoms in patients with diabetes [23].

The VEGF +405 and VEGF -460 gene polymorphisms were not shown to be associated with peripheral neuropathy in our patients. However whether VEGF accounts for the differential vulnerability to neuropathy amongst patients of different ethnic background remains to be determined. In our study, the Indo-Asian ethnic group with the lowest prevalence of neuropathy had the highest frequency of the +405 GG VEGF genotype, which has been shown to be associated with raised plasma VEGF levels [11]. It is reported that patients with type 2 diabetes of Indo-Asian and African-Caribbean origin are less likely to develop neuropathy and foot ulceration compared with

Table 4 VEGF +405 genotypes in type 2 diabetes patients from Indo-Asian, African Caribbean and Caucasian origin

\begin{tabular}{llll}
\hline VEGF + 405 genotypes & Indo-Asian & African-Caribbean & Caucasian \\
\hline CG (\%) & $13(32.5)^{\mathrm{a}, \mathrm{b}}$ & $36(48.0)$ & $79(57.25)$ \\
CC (\%) & $0(0)$ & $5(6.7)$ & $6(4.35)$ \\
GG (\%) & $27(67.5)^{\mathrm{a}, \mathrm{b}}$ & $34(45.3)$ & $53(38.4)$ \\
$\mathrm{C}(\%)$ & $13(16.25)^{\mathrm{c}, \mathrm{d}}$ & $46(30.67)$ & $91(32.97)$ \\
$\mathrm{G}(\%)$ & $67(83.75)^{\mathrm{c}, \mathrm{d}}$ & $104(69.33)$ & $185(67.03)$ \\
\hline
\end{tabular}

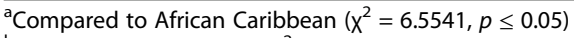

${ }^{\mathrm{b}}$ Compared to Caucasian $\left(X^{2}=11.2541, p \leq 0.005\right)$

${ }^{c}$ Compared to African Caribbean $\left(x^{2}=5.6858, p \leq 0.02\right)$

${ }^{d}$ Compared to Caucasian $\left(x^{2}=8.3857, p \leq 0.005\right)$ those of Caucasian origin [7-10]. In our cohort though we found a near 3-fold greater prevalence of clinically evident peripheral neuropathy in the Caucasian patient group compared with the non-Caucasian group. The relatively high prevalence of peripheral neuropathy in this cohort is in part due to these patients being attendees of a secondary care centre and there are differences in methodologies reported in different centres for case finding. In contrast to other studies we used the $10 \mathrm{~g}$ monofilament in consecutive patients, whereas other studies used the neurothesiometer and biothesiometer in selected patients $[8,10,24]$. Patients of non-Caucasian background are generally poorly represented in research studies in the UK and the lack of standardisation in the methodologies to diagnose neuropathy may have affected the reported

Table 5 Genotype and Allele frequencies of the VEGF +405 gene polymorphisms in patients with and without neuropathy

\begin{tabular}{lll}
\hline VEGF + 405 Polymorphism & With Neuropathy & $\begin{array}{l}\text { Without } \\
\text { neuropathy }\end{array}$ \\
\hline 1) Whole population Genotypes & $N=35$ & $N=264$ \\
CG (\%) & $18(51.4)$ & $134(50.8)$ \\
GG (\%) & $16(45.7)$ & $119(45.1)$ \\
CC (\%) & $1(2.9)$ & $11(4.2)$ \\
C (\%) & $21(29.58)$ & $156(29.55)$ \\
G (\%) & $50(70.42)$ & $372(70.45)$ \\
2) Type 2 diabetes Genotypes & $N=32$ & $N=221$ \\
CC (\%) & $1(3.1)$ & $10(4.5)$ \\
CG (\%) & $18(56.3)$ & $110(49.8)$ \\
GG (\%) & $13(40.6)$ & $101(45.6)$ \\
C (\%) & $20(31.25)$ & $130(29.41)$ \\
G (\%) & $44(68.75)$ & $312(70.59)$ \\
\hline
\end{tabular}


prevalence [25]. However, if the prevalence of neuropathy is similar between these ethnic groups there would have been clear ethnic similarities in the rates of penetrative ulceration and limb amputation. Insensitivity to the $10 \mathrm{~g}$ monofilament increases the 2 year risk of ulceration nearly 3 -fold [26]. However, the rates of lower limb amputation amongst patients with diabetes of Indo-Asian compared to Caucasian origin are significantly lower in the UK [27].

In this cross-sectional study, the VEGF +405 polymorphism distribution was similar between patients of African-Caribbean and Caucasian origin and the frequencies of the $\mathrm{G}$ and $\mathrm{C}$ alleles were similar between the ethnic groups. These findings are in line with the only two other studies that looked at VEGF +405 polymorphism and ethnicity $[28,29]$. Moreover, the frequencies found for the VEGF +405G Allele in this cohort of patients of Caucasian and African-Caribbean origin (67\% and 69\%, respectively) are similar to those reported in American whites and black individuals without diabetes and vascular disease [28] and in white and black Brazilians [29]. These findings suggest that VEGF +405 genotype distribution and allele frequencies are similar across ethnic groups when comparing Caucasian and African-Caribbean cohorts in the presence or absence of diabetes.

Our study found that VEGF +405 GG genotype was more common in patients of Indo-Asian origin in comparison to African-Caribbean and Caucasian patients. In addition, the frequency of the VEGF $+405 \mathrm{G}$ allele was higher in the Indo-Asian patients (83.75\%) per comparison to African-Caribbean and Caucasian patients (67\% and $69 \%$, respectively). Previous research demonstrated that Lipopolysaccharide stimulated peripheral blood mononuclear cell VEGF protein production was highest among individuals who were VEGF +405GG [11] and high expression of VEGF was protective for ischemic neuronal damage $[30,31]$. It can be postulated that VEGF +405GG has a protective role against neuropathy and may explain why patients of Indo-Asian origin, should they develop ulceration may have better rates of healing, and therefore lower rates of amputation [26]. Furthermore, the VEGF -460 polymorphism, which has not been correlated to plasma VEGF concentration [11] was not different between the ethnic groups.

Although, this study did not measure serum VEGF concentration, elevated serum VEGF levels have been reported in healthy subjects with the VEGF +405CC genotype and not the VEGF +405 GG [12]. Lambrechts and colleagues [32] demonstrated that production of large-VEGF isoform with the VEGF +405G allele in cell extracts was $20 \%$ lower in comparison to VEGF $+405 \mathrm{C}$ allele. It has also been shown that haplotypes of VEGF $-2578 \mathrm{~A} /-1154 \mathrm{~A} /+405 \mathrm{G}$ and $-2578 \mathrm{~A} /-1154 \mathrm{G} /+405 \mathrm{G}$ in the VEGF promoter/leader lowered circulating VEGF levels in vivo and reduced VEGF gene transcription [32]. Similar results were reported in cultured human myoblasts that analysed the effects of the VEGF $-2578 /-1154 /+405$ promoter region haplotype on VEGF gene expression [28]. Moreover, ethnic differences in VEGF haplotypes $-2578 \mathrm{C} /-1154 \mathrm{G} /+405 \mathrm{G}$ were reported to be more common in Black than White Brazilian individuals even though these groups had similar profile in VEGF +405 genotype [29]. Collectively, these studies and our study findings suggest that ethnic differences in various VEGF polymorphisms exist, and the possible association between these VEGF genotypes including VEGF +405 might influence circulating VEGF concentrations.

The prevalence of peripheral neuropathy in this realworld selected cohort is in agreement with previous studies with regards to the vulnerability of Caucasian patients to peripheral neuropathy in comparison to other ethnic groups [7, 8, 24]. Glycaemic control is the major factor in the development of diabetic neuropathy $[5,24,33]$. In the current study, there were no differences in HbA1c in the patients with, compared to those without neuropathy. Furthermore, in correcting for glycaemic control nonCaucasian ethnic group appears to be a protective factor for the development of neuropathy.

A number of studies in small groups of patients have identified an association between diabetic neuropathy and VEGF gene polymorphisms, but not the propensity to develop diabetic neuropathy or the healing process. The VEGF gene SNP at $-7 * \mathrm{C} / \mathrm{T}$ was associated with diabetic neuropathy in type 1 diabetic patients of British Caucasian origin [34]. Another VEGF polymorphism that was associated with diabetic neuropathy is VEGF $936 \mathrm{C} / \mathrm{T}$ in type 2 diabetic Chinese patients [35]. The latest VEGF polymorphism that was reported to be associated with neuropathy is the Insertion/deletion VEGF gene that was studied in type 2 diabetes population [36].

\section{Conclusions}

The present study is the first to examine the distribution of VEGF +405 and VEGF -460 genotypes in AfricanCaribbean, Indo-Asian and Caucasian patients with diabetes and the association of these genotypes with peripheral neuropathy. Although there was a difference in the VEGF + 405 polymorphism and the frequencies of $\mathrm{G}$ and $C$ alleles between the ethnic groups, this study did not find any association with diabetic neuropathy regardless of diabetes type or ethnic origin. The results may suggest that neither VEGF +405 nor VEGF -460 polymorphisms are involved with diabetic peripheral neuropathy. However the complexity of VEGF gene expression and the small sample size of the enrolled population limits our conclusions. These findings support a hypothesis that the VEGF +405 genotype may confer protection from developing peripheral neuropathy and therefore the risk of developing foot ulceration and lower limb amputation in patients of 
non-Caucasian origin in the UK. This study results reiterate the need for further research into the possible relationship between VEGF genotypes, circulating VEGF concentrations and differential vulnerability to peripheral neuropathy in patients with diabetes of different ethnic backgrounds.

\section{Abbreviations}

PCR: Polymerase chain reaction; VEGF: Vascular Endothelial Growth Factor

\section{Acknowledgments}

We thank Dr. Kamini Kalidas for technical advice on PCR.

\section{Funding}

This work was supported by St George's Hospital Charity [Diabetes Research Fund- AONS]. The funding body had no involvement in any stage of the study.

\section{Availability of data and materials}

The datasets used and/or analysed during the current study available from the corresponding author on reasonable request.

\section{Authors' contributions}

KZ researched the data, performed the experiments and contributed to the writing of the manuscript. LT advised on genotyping and contributed to the writing of the manuscript. All authors read and approved the final manuscript. KAE researched the data, designed the study, and contributed to the writing of the manuscript.

\section{Ethics approval and consent to participate}

This study has received ethical approval from the ethics committee of the Whittington Hospital National Health Service Trust. Written, informed consent was provided by all patients enrolled in the study prior to participation.

\section{Competing interests}

The authors declare that they have no competing interests.

\section{Publisher's Note}

Springer Nature remains neutral with regard to jurisdictional claims in published maps and institutional affiliations.

\section{Author details}

'Department of Cellular and Molecular Medicine, St. Georges University of London, London, UK. ${ }^{2}$ Department of Biomedical Sciences, University of Westminster, London, UK. ${ }^{3}$ St Georges University Hospitals NHS Foundation Trust, Thomas Addison Diabetes Unit, London, UK.

Received: 23 February 2017 Accepted: 22 June 2017

Published online: 29 June 2017

\section{References}

1. Boulton AJM. Management of diabetic peripheral neuropathy. Clin Diabetes. 2005:23:9-15.

2. Vinik Al, Nevoret ML, Casellini C, Parson H. Diabetic neuropathy. Endocrino Metab Clin N Am. 2013;42(4):747-87.

3. Centers for Disease Control and Prevention. National Diabetes Statistics Report: Estimates of Diabetes and Its Burden in the United States. Atlanta: $U$. S. Department of Health and Human Services; 2014.

4. Witzel II, Jelinek HF, Khalaf K, Lee S, Khandoker AH, Alsafar H. Identifying Common Genetic Risk Factors of Diabetic Neuropathies. Front Endocrinol (Lausanne). 2015;6:88.

5. Papanas N, Vinik Al, Ziegler D. Neuropathy in prediabetes: does the clock start ticking early? Nat Rev Endocrinol. 2011;7:682-90.

6. Sosenko JM. The prevalence of diabetic neuropathy according to ethnicity. Curr Diab Rep. 2009;9(6):435-9.

7. UK Prospective Diabetes Study. XII: Differences between Asian, Afro-Caribbean and white Caucasian type 2 diabetic patients at diagnosis of diabetes. UK Prospective Diabetes Study Group. Diabet Med. 1994;11(7):670-7.

8. Winkley K, Thomas SM, Sivaprasad S, Chamley M, Stahl D, Ismail K, et al. The clinical characteristics at diagnosis of type 2 diabetes in a multi-ethnic population: the South London Diabetes cohort (SOUL-D). Diabetologia. 2013:56:1272-81.

9. Cohen JA, Jeffers BW, Faldut D, Marcoux M, Schrier RW. Risks for sensorimotor peripheral neuropathy and autonomic neuropathy in non-insulin-dependent diabetes mellitus (NIDDM). Muscle Nerve. 1998;21(1):72-80.

10. Abbott CA, Chaturvedi N, Malik RA, Salgami E, Yates AP, Pemberton PW, et al. Explanations for the Lower Rates of Diabetic Neuropathy in Indian Asians Versus Europeans. Diabetes Care. 2010;33(6):1325-30.

11. Watson CJ, Webb NJA, Bottomley MJ, Brenchley PEC. Identifications of polymorphisms within the vascular endothelial growth factor (VEGF) gene: correlation with variation in VEGF protein production. Cytokine. 2000;12(8):1232-5.

12. Awata T, Inoue K, Kurihara S, Onkubo T, Watanabe M, Inukai K, et al. A Common Polymorphism in the 5'-Untranslated Region of the VEGF Gene is associated with Diabetic Retinopathy in Type 2 Diabetes. Diabetes. 2002;51:1635-9.

13. Summers AM, Coupes BM, Brennan MF, Ralph SA, Short CD, Brenchley PE. VEGF -460 genotype plays an important role in progression to chronic kidney disease stage 5. Nephrol Dial Transplant. 2005;20(11):2427-32.

14. Gong J-Y, Sun Y-H. Association of VEGF Gene Polymorphisms with Diabetic Retinopathy: A Meta-Analysis. PLoS One. 2013:8(12):e84069.

15. Ray D, Mishra M, Ralph S, Read I, Davies R, Brenchley P. Association of the VEGF gene with proliferative diabetic retinopathy but not proteinuria in diabetes. Diabetes. 2004;53(3):861-4.

16. Bleda S, De Haro J, Varela C, Esparza L, Ferruelo A, Acin F. Vascular endothelial growth factor polymorphisms are involved in the late vascular complications in Type II diabetic patients. Diab Vasc Dis Res. 2012;9(1):68-74.

17. Miller SA, Dykes DD, Polesky HF. A simple salting out procedure for extracting DNA from human nucleated cells. Meth Nucleic Acids Res. 1988;16(3):1215.

18. Parenti A, Brogelli L, Filippi S, Donnini S, Ledda F. Effect of hypoxia and endothelial loss on vascular smooth muscle cell responsiveness to VEGF-A: role of flt-1/NEGF-receptor-1. Cardiovasc Res. 2002:55(1):201-12.

19. Schratzberger $P$, Schratzberger $G$, Silver M, Curry C, Kearney M, Magner M, et al. Favorable effect of VEGF gene transfer on ischemic peripheral neuropathy. Nat Med. 2000;6(4):405-13.

20. Schratzberger P, Walter DH, Rittig K, Bahlmann FH, Pola R, Curry C, et al. Reversal of experimental diabetic neuropathy by VEGF gene transfer. J Clin Invest. 2001;107(9):1083-92.

21. Samii A, Unger J, Lange W. Vascular endothelial growth factor expression in peripheral nerves and dorsal root ganglia in diabetic neuropathy in rats. Neurosci Lett. 1999;62(3):159-62.

22. Deguchi T, Hashiguchi T, Horinouchi S, Uto T, Oku H, Kimura K, et al. Serum VEGF increases in diabetic polyneuropathy, particularly in the neurologically active symptomatic stage. Diabet Med. 2009;26:247-52.

23. Ropper AH, Gorson KC, Gooch CL, Weinberg DH, Pieczek A, Ware JH, et al. Vascular endothelial growth factor gene transfer for diabetic polyneuropathy: a randomized, double-blinded trial. Ann Neurol. 2009;65(4):386-93.

24. Sorensen L, Molyneaux L, Yue DK. Insensate versus painful diabetic neuropathy: the effects of height, gender, ethnicity and glycaemic control. Diabetes Res Clin Pract. 2002;57(1):45-51.

25. Moxey PW, Gogalniceanu P, Hinchliffe RJ, Loftus IM, Jones KJ, Thompson $\mathrm{MM}$, et al. Lower extremity amputations-a review of global variability in incidence. Diabet Med. 2011:28(10):1144-53.

26. Abbott CA, Carrington AL, Ashe H, Bath S, Every LC, Griffiths J, et al. North-West Diabetes Foot Care Study. The North-West Diabetes Foot Care Study: incidence of, and risk factors for, new diabetic foot ulceration in a community-based patient cohort. Diabet Med. 2002;19(5):377-84.

27. Gujral JS, McNally PG, O'Malley BP, Burden AC. Ethnic differences in the incidence of lower extremity amputation secondary to diabetes mellitus. Diabet Med. 1993;10(3):271-4.

28. Prior SJ, Hagberg JM, Paton CM, Douglass LW, Brown MD, McLenithan JC, et al. DNA sequence variation in the promoter region of the VEGF gene impacts VEGF gene expression and maximal oxygen consumption. Am J Physiol Heart Circ Physiol. 2006;290(5):H1848-55.

29. Muniz JJ, Izidoro-Toledo TC, Metzger IF, Sandrim VC, Tanus-Santos JE. Interethnic differences in the distribution of clinically relevant vascular endothelial growth factor genetic polymorphisms. DNA Cell Biol. 2009;28(11):567-72.

30. Sondell M, Lundborg G, Kanje M. Vascular endothelial growth factor has neurotrophic activity and stimulates axonal outgrowth, enhancing cell survival and Schwann cell proliferation in the peripheral nervous system. J Neurosci. 1999;19(14):5731-40. 
31. Tremolada G, Lattanzio R, Mazzolari G, Zerbini G. The therapeutic potential of VEGF inhibition in diabetic microvascular complications. Am J Cardiovasc Drugs. 2007;7:393-8.

32. Lambrechts $D$, Storkebaum E, Morimoto M, Del-Favero J, Desmet F, Marklund SL, et al. VEGF is a modifier of amyotrophic lateral sclerosis in mice and humans and protects motoneurons against ischemic death. Nat Genet. 2003;34(4):383-94.

33. Yagihashi S, Mizukami H, Sugimoto K. Mechanism of diabetic neuropathy: where are we now and where to go? J Diabetes Invest. 2011;2:18-32.

34. Tavakkoly-Bazzaz J, Amoli MM, Pravica V, Chandrasecaran R, Boulton AJM, Larijani B, et al. VEGF gene polymorphism association with diabetic neuropathy. Mol Biol Rep. 2010;37:3625-30.

35. Zhang $X$, Sun Z, Jiang H, Song $X$. Relationship between single nucleotide polymorphisms in the $3^{\prime}$-untranslated region of the vascular endothelial growth factor gene and susceptibility to diabetic peripheral neuropathy in China. Arch Med Sci. 2014;10(5):1028-34.

36. Stoian A, Bacârea A, Moțățăianu A, Stoian M, Gliga F, Bacârea V, et al. Vascular Endothelial Growth Factor Insertion/Deletion gene polymorphism in patients with type 2 diabetes and diabetic peripheral polyneuropathy. Rom Rev Lab Med. 2014;22(2):165-72.

\section{Submit your next manuscript to BioMed Central} and we will help you at every step:

- We accept pre-submission inquiries

- Our selector tool helps you to find the most relevant journal

- We provide round the clock customer support

- Convenient online submission

- Thorough peer review

- Inclusion in PubMed and all major indexing services

- Maximum visibility for your research

Submit your manuscript at www.biomedcentral.com/submit 